\title{
Forty-four years of ScienceAsia: from a domestic journal to an international journal
}

\author{
Worachart Sirawaraporn \\ Emeritus Professor of Biochemistry and Chief-Editor, ScienceAsia \\ e-mail: worachart.sir@maidol.ac.th, editor@scienceasia.org
}

\begin{abstract}
ScienceAsia, currently an official journal of the Science Society of Thailand and National Research Council of Thailand, will be 44 years old when the Science Society of Thailand celebrates its 70th anniversary in 2018. Needless to say, the journal has had quite a long journey and has faced countless up-and-down periods during its development. This article focuses on the editor's view and the strategies to develop a journal from domestic scale to international level, using ScienceAsia as a case study. A number of challenges which should be considered and adopted for the management of journals to meet international recognition are discussed.
\end{abstract}

KEYWORDS: Journal of the Science Society of Thailand, journal management, current and future status of ScienceAsia

\section{ABOUT THE JOURNAL}

In 1975, the Science Society of Thailand saw its first launch of a journal called Journal of the Science Society of Thailand (JSST). The journal, initially aimed to be a platform for publishing research generated by Thai researchers, gradually developed with increasing recognition from overseas researchers. It was not until 1999 that the journal adopted its new name ScienceAsia to broaden coverage to international communities ${ }^{1,2}$.

ScienceAsia publishes research work from both Thai and overseas researchers. Starting from 2011, the journal has been receiving an increasing number of intercontinental manuscripts, reflecting an increasing visibility of the journal (Fig. 1). This has later led to the change of frequency of the journal to publish bimonthly instead of quarterly since 2013 (Fig. 2).

Currently, ScienceAsia receives submission of manuscripts worldwide up to 1000 manuscripts per year. The impact factor for ScienceAsia in 2018 is 0.447 , a slightly higher than that in 2016 (0.343). Analysis from Incites Journal Citation Report (https://apps.clarivate.com/) revealed that the top 3 countries that published with ScienceAsia during 2015-2017 were Thailand (81 articles), China (38 articles), and Malaysia (19 articles). For Thailand, the top 4 organizations publishing with the journal were Chulalongkorn University (19 articles), Kasetsart University (13 articles), Prince of Songkla University (13 articles), and Mahidol University (11 articles).

Managing a journal is not so difficult, but sub-

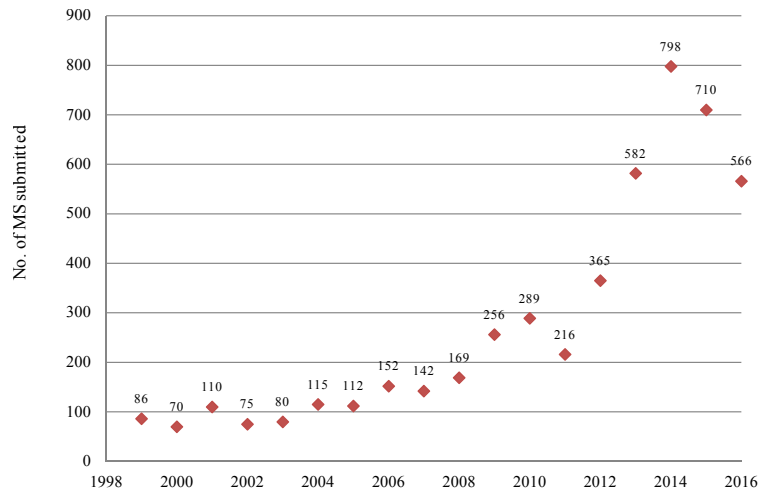

Fig. 1 Number of manuscripts submitted to ScienceAsia during 1999-2016.

stantial time and effort are required by the managing team prior to be successful and becoming an internationally recognized journal. One of the greatest challenges in is for the team to maintain the sustainability of the journal by having adequate number of quality papers published in each issue. It is extremely important but difficult to always maintain the high standards and continuity of the journal. Failure to do so will only lead to more serious situations of delay publication, broken volumes or temporary cessation of the journal. If this happens, it would then be very difficult to attract submissions from potential authors who may decline to submit papers to a journal which has a record of an inconsistent publishing schedule.

One of the key issues in addressing the efficiency of the journal is to have a dedicated journal website with easy submission procedure. Certainly this is 


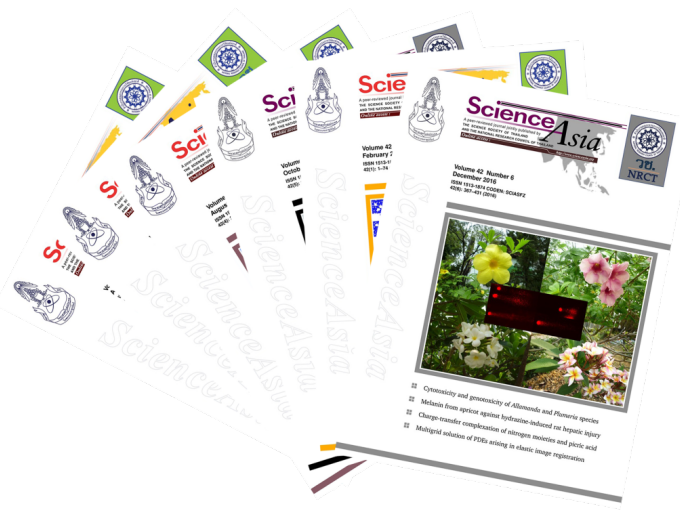

Fig. 2 Cover pages of different issues of ScienceAsia.

not the only issue, but is among the first requirements to be considered for a journal or publisher. For ScienceAsia, the journal has a dedicated website www.scienceasia.org with the necessary software developed in-house which can handle unlimited number of submitted manuscripts and communicate efficiently with authors and reviewers. Clearly, the number of submitted manuscripts cannot be counted as the success of the journal. Analysis of these manuscripts revealed that there remain numerous manuscripts which are out of the scope of the journal and some are unsuitable for publication in ScienceAsia.

Peer-review process is another time-consuming step in the publication process. For some of the manuscripts, it is difficult to find reviewers willing to read them, not because of scientific reasons, but simply because of poor English of the manuscript. It is important for the authors to make sure that the English in the manuscript is correct and understandable by asking a native speaking colleague to help correct the manuscript prior to submission. Nonetheless, this may not help to reduce the overall duration of the publication timeline, as it is well known that all the renowned reviewers are extremely busy, and new reviewers need to be invited if those reviewers decline to read the manuscript. To avoid potential 'decline to read' by the invited reviewers, the editorial team of ScienceAsia always extensively review the manuscript with respect to scientific content, plagiarism, scientific novelty of the manuscript, proper preparation of the manuscript, figures, tables, etc., prior to send out for peerreview. Lately, ScienceAsia also has also included Mathematical Reviews Database (MSC) codes which indicates the subject classification of the paper based on the Mathematics Subject Classification Scheme in each mathematical paper to facilitate tracking of the manuscript. In addition, all mathematics papers are requested to be submitted in a LaTeX format (see Instructions for Authors; www.scienceasia.org/ instruction_authors.php). Although ScienceAsia has a timeline for each step of the publication process, it should be noted that publication of the manuscript could be delayed due to many other factors. Hence it is advisable for the authors to allocate enough time and allow the editorial team of the journal to work.

To further expand the visibility of the journal and the contents of the published manuscripts, ScienceAsia applied to be a member of Crossref (www. crossref.org), a leading digital object identifiers registration agency, and registered the for the content of each manuscript (metadata) to Crossref. This will assign a persistent link as well as a persistent identifier to each manuscript, and therefore ensures rapid identification and tracking of the manuscripts published by ScienceAsia, as well as increases the visibility of the journal on a global scale.

Plagiarism seems not to be a problem thus far for manuscripts submitted to ScienceAsia, although there was a case by a Thai author complaining duplication of his article published in ScienceAsia a few years ago. The problem of this case was solved by writing an email to the editor of the journal which published the duplicated article and requested the journal to withdraw that article and blacklisted the authors of that article. With the availability of computer software and various tools nowadays, plagiarism $^{3}$, self-citation ${ }^{4}$, duplication ${ }^{5}$ can easily be detected by most of the journals and publishers. The current problem, however, seems to be the so called 'predatory journals'. These predatory journals are generally open-access journals and can either be hijack or cyber squat journals which create fake database and defrauding authors' publication fee, or use scam emails to steal authors' information. There are numerous suggestions for authors to avoid getting into these predatory journals. Generally, predatory journals often have fake database website names and email addresses, or unreasonable number of published articles, or emails soliciting to submit articles, etc. Preliminary awareness and precaution must be taken to evaluate the journal before submission of the manuscript, or consult Beall's list of predatory journals and publishers at https://beallslist.weebly.com/.

With respect to several journal metrices currently available to quantitative evaluate the jour- 
nals, impact factor seems to be the most widely used for the evaluation of both journals and performance of the authors. The impact factor of a journal can be simply calculated as the average value of citations per paper published in the journal during two previous years. Other alternative metrices are also available, but it should be noted that no metric is perfect. Hence, it is recommended not to rely on these metrices too much when evaluating the journals, researchers, or institution. Despite this precaution, most authors still use impact factor of the journal as the primary consideration upon journal selection for the papers. The other consideration is how fast the manuscript can be published. A survey was carried out in India to determine what authors thought about the academic publishing system and what would be the decisive factors in selecting a journal ${ }^{6}$. The survey results revealed that both impact factor and timeliness of the publication are among the first two aspects which influence the decision of selecting a journal.

In conclusion, ScienceAsia has gradually been developed from domestic journal to an internationally recognized journal, and is currently indexed in many international databases with increasing impact factor. The journal has a long journey with upand-down situations at some points. It is important for the journal to maintain its role for Thai science, and improve its quality with increased visibility, and hopefully engage in relevant international activities when the journal has enough resources and manpower. It is hoped that ScienceAsia would grow bigger and contribute more towards the development of science in Thailand for years to come.

\section{REFERENCES}

1. Svasti MRJ (2005) Thirty Years of ScienceAsia, Journal of the Science Society of Thailand. Sci Asia 31, 1-3.

2. Yuthavong Y (2018) ScienceAsia, Journal of the Science Society of Thailand, reflects maturation of science in Thailand. Sci Asia 44S, 1-3.

3. Mohammed RAA, Shaaban OM, Mahran DG, Attellawy HN, Makhlof A, Albasri A (2015) Plagiarism in medical scientific research. J Taibah Univ Med Sci 10, 6-11.

4. Flatt JW, Blasimme A, Vayena E (2017) Improving the measurement of scientific success by reporting a selfcitation index. Publications 5, 20.

5. von Elm E, Poglia G, Walder B, Tramèr MR (2004) Different patterns of duplicate publication: an analysis of articles used in systematic reviews. JAMA 291, 974-80.

6. D'Souza B, Kulkarni S, Cerejo C (2018) Authors' perspectives on academic publishing: initial observations from a large-scale global survey. Sci Ed 5, 39-43. 